\title{
Hypertension in Sudanese individuals and associated risk factors: the critical intersection between salt and sugar intake
}

\author{
Heitham Awadalla ${ }^{1}$, Nehad Elsheikh Elmak ${ }^{2}$, Eman F. El-Sayed ${ }^{2}$, Ahmed O. Almobarak ${ }^{3}$, Wadie M. \\ Elmadhoun $^{4}$, Mugtaba Osman ${ }^{5}$, Sufian K. Noor ${ }^{6}$, Mohamed H. Ahmed ${ }^{7}$ \\ ${ }^{1}$ Department of Community Medicine, Faculty of Medicine, University of Khartoum, Khartoum, Sudan; ${ }^{2}$ Public and Tropical Health Program, \\ Graduate College, University of Medical Sciences and Technology, Khartoum, Sudan; ${ }^{3}$ Department of Pathology, Faculty of Medicine, University of \\ Medical Sciences and Technology, Khartoum, Sudan; ${ }^{4}$ Department of Pathology, Faculty of Medicine and Health Sciences, Nile Valley University, \\ Atbara, Sudan; ${ }^{5}$ Armed Forces Centre for Psychiatric Care, Taif, Saudi Arabia; ${ }^{6}$ Department of Medicine, Faculty of Medicine and Health Sciences, \\ Nile Valley University, Sudan; ${ }^{7}$ Department of Medicine and HIV Metabolic Clinic, Milton Keynes University Hospital NHS Foundation Trust, \\ Eaglestone, Milton Keynes, Buckinghamshire, UK \\ Contributions: (I) Conception and design: H Awadalla, AO Almobarak, MH Ahmed; (II) Administrative support: H Awadalla, AO Almobarak, MH \\ Ahmed, NE Elmak, EF El-Sayed, SK Noor, WM Elmadhoun; (III) Provision of study materials or patients: H Awadalla, AO Almobarak, MH \\ Ahmed, NE Elmak, EF El-Sayed; (IV) Collection and assembly of data: H Awadalla, AO Almobarak, MH Ahmed, NE Elmak, EF El-Sayed, M \\ Osman; (V) Data analysis and interpretation: H Awadalla, MH Ahmed, M Osman, SK Noor, WM Elmadhoun, AO Almobarak; (VI) Manuscript \\ writing: All authors; (VII) Final approval of manuscript: All authors. \\ Correspondence to: Mohamed H. Ahmed. Department of Medicine and HIV Metabolic Clinic, Milton Keynes University Hospital NHS Foundation \\ Trust, Eaglestone, Milton Keynes, Buckinghamshire, UK. Email: elziber@yahoo.com.
}

\begin{abstract}
Background: Hypertension is common problem across the globe. The aim of this study was to assess the prevalence of hypertension and impact of salt and sugar intake in Sudanese population.

Methods: A descriptive cross sectional study, included 323 of participants in Khartoum state. The data collection was performed to gather demographic information, physical activity and dietary habits. In addition to measurement of blood pressure (BP), weight and height measurement for calculation of body mass index (BMI). Results: Among the 323 respondents (males were 171), 29 (9\%) are known hypertensive, 60 (18.6\%) are diagnosed to be hypertensive. Therefore, the prevalence of hypertension is $27.6 \%$. Hypertension was significantly associated with male sex, increasing age, obesity, low physical activity, salt and sugar intake. Logistic regression analysis showed that increasing age, obesity and high sugar intake are absolute predictors for hypertension in Sudanese population.

Conclusions: The prevalence of hypertension was 27.6\%. Hypertension in Sudanese individuals was associated with high sugar and salt intake, obesity and increase in age. Therefore, decreasing sugar and salt intake should be advocated by health authorities and the public in Sudan.
\end{abstract}

Keywords: Hypertension; salt intake; sugar intake; Sudan

Submitted Jan 14, 2018. Accepted for publication Apr 02, 2018.

doi: $10.21037 / \mathrm{cdt} .2018 .04 .05$

View this article at: http://dx.doi.org/10.21037/cdt.2018.04.05

\section{Introduction}

Africa is facing an increase in level of non-communicable diseases and this is likely due to parallel increase in obesity epidemic associated with economic growth (1). In cross sectional study in elderly adult population in Tanzania, Sudan and Nigeria, the burden of noncommunicable diseases (NCDs) was found to be $81.0 \%$ $(\mathrm{n}=708)$ of admissions $(\mathrm{n}=874)$, and tuberculosis, malaria, and the human immunodeficiency virus and acquired immunodeficiency syndrome accounted for $4.6 \%(n=40)$. Cerebrovascular accident $(\mathrm{n}=224,25.6 \%)$ was the most 
common reason for admission, followed by cardiac or circulatory dysfunction $(\mathrm{n}=150,17.2 \%)$. Rate of hypertension in these countries was $40.2 \%$ almost similar to rate of hypertension in UK (45.8\%) (2). Importantly, several studies showed high prevalence of hypertension in different African countries. For instance, the trial of hypertension in North Africa (Epidemiological Trial of Hypertension in North Africa), an international, multicenter, epidemiological, cross-sectional study conducted in Algeria, Tunisia, and Morocco, showed total prevalence of hypertension was $45.4 \%$ (3). Furthermore, the prevalence of hypertension in urban areas in Namibia, Nigeria, Tunisia and Ethiopia was found to be $32 \%, 33 \%, 28.9 \%$ and $30 \%$, respectively (4-7). Therefore, the Pan-African Society of Cardiology (PASCAR) called for publication of a set of clinical guidelines for the prevention and management of hypertension in Africa in collaboration with the World Heart Federation (WHF) (1). Sudan is located in the heart of Africa and prevalence of hypertension in different regions and ethnic groups were found to be high. For instance, in Urban population in north of Sudan the prevalence of hypertension was estimated to be more than $30 \%$ (8). While in rural population the prevalence was estimated to be between $15 \%$ to $38 \%$ in Sudan $(9,10)$. Importantly, the prevalence of hypertension in Nubia ethnic population in South of Sudan was around 50\% (11). Therefore, the aim of this study is to establish prevalence of hypertension in Khartoum region and whether salt and sugar intake can be risk factors.

\section{Methods}

\section{Patients and methods}

\section{Study design}

A descriptive cross-sectional community-based study was conducted in Khartoum.

\section{Exclusion criteria}

Individuals below 18 years, or pregnant ladies were excluded from this survey. As the setting is not hospital-based setting; we have no more restriction in selection based on medical condition or comorbidities.

\section{Data collection}

The STEP wise approach for non-communicable diseases surveillance of the World Health Organization (WHO) was used for data collection (12). A standardized structured questionnaire was used to gather demographic and behavioral information. Each participant was questioned for demographic data, past medical history, risk factors and family history of hypertension. Data was collected through an interviewer administered pre-tested questionnaire. Furthermore, body weight and height were measured to calculate the body mass index (BMI). Blood pressure (BP) was measured using the standardized technique (13). Study was conducted in Khartoum, which is the capital of Sudan. The study populations also included people coming from different states who visit Khartoum regularly for purpose of study, work or businesses. Therefore, the sample size can be representative for a sample.

\section{Anthropometric measurements}

Anthropometric measurements were taken using standardized technique and calibrated equipment. BMI was calculated by the formula: weight in kilograms divided by height in meters squared. BMI defined $<18.5 \mathrm{~kg} / \mathrm{m}^{2}$ as underweight, $18.5-24.9 \mathrm{~kg} / \mathrm{m}^{2}$ normal, $25-29.9 \mathrm{~kg} / \mathrm{m}^{2}$ overweight and $>30 \mathrm{~kg} / \mathrm{m}^{2}$ as obesity (13). According to the WHO guidelines, less than $10 \%$ of total energy intake should be from free sugars for a person of healthy body weight consuming approximately 2,000-2,500 calories per day (14), which is approximately 200 calories (equal to 12 tea spoons and this assessed by the questionnaire). Due to tropical weather in Sudan and high consumption of sweetened Beverage, sugar intake was also assessed using the beverage intake questionnaire. Physical activity was estimated using validated global physical activity questionnaire. The questionnaire used classified salt intake into mild, moderate and high. Salt intake more than 5 gram per day was considered high (15).

\section{BP measurement}

$\mathrm{BP}$ was measured on the sitting position using a calibrated portable mercury sphygmomanometer, with appropriate cuff size. The average of three readings each taken after 15 minutes rest was recorded. BP levels were classified according to the Criteria of the Seventh Report of the Foint National Committee on Prevention, Detection, Evaluation and Treatment of High Blood Pressure (16).

Definitions of the BP recordings were as follows:

- Normal BP is a systolic BP less than $120 \mathrm{mmHg}$ and a diastolic BP less than $80 \mathrm{mmHg}$;

* Prehypertension is a systolic BP between 120-139 $\mathrm{mmHg}$ and a diastolic BP between $80-89 \mathrm{mmHg}$;

* Stage one hypertension: is a systolic of 140-159 
$\mathrm{mmHg}$, and/or a diastolic of 90-99 $\mathrm{mmHg}$;

* Stage two hypertension: is a systolic of $160 \mathrm{mmHg}$ or more, and/or a diastolic of $100 \mathrm{mmHg}$ or more.

\section{Ethical approval}

An ethical clearance of the research was obtained from the Ethical Committee of the Faculty of Medicine-University of Medical Science and Technology, Khartoum, Sudan (IRB No. 00008867).

\section{Statistical analysis}

The data generated was coded, validated and analyzed using Statistical Package for Social Sciences (SPSS) version 20 (IBM Statistics, USA). We used the simple formula for sample size calculation taking probability of salt and sugar intake approximately $30 \%$ of the population according to previous studies; power of $80 \%$ with $Z=1.96$, and degree of errors $=0.05$.

We have used following formula:

$$
\mathrm{N}=\frac{\mathrm{Z}^{2} \mathrm{PQ}}{\mathrm{D}^{2}}
$$

$\mathrm{N}=$ required sample size [323]; $\mathrm{Z}=1.96$ (is the value of the standard normal distribution that corresponds to twotailed significance level of 0.05 ); $\mathrm{P}=30 \%$ or 0.3 (proportion of exposure among study population); $\mathrm{Q}=0.7(1-\mathrm{p})$ (proportion of unexposed study population); $\mathrm{D}=0.05$ (degree of error was taken as 0.05).

Pearson chi squared and $t$-test tests were used to test for significance between proportions and means respectively. $\mathrm{P}$ value below 0.05 was considered statistically significant. We have also tested the normality in relation to the distribution of numerical variables. There was no stratification at selection stage. Age was taken as continuous variable; latter using the SPSS we stratified into groups (younger age, middle age and elderly) for comparison using Chi square test. Binary logistic regression was used to assess the absolute predictors of hypertension. The main variables analyzed were age, sex, BMI, Physical exercise, sugar intake, and salt intake.

\section{Results}

\section{Sociodemographic variables}

Among 323 respondents, 29 (9\%) are known hypertensive, $60(18.6 \%)$ were diagnosed to be hypertensive, 145 (44.9\%) are pre-hypertensive, and 89 (27.6\%) have normal BP. Male representation in the sample was $171(52.9 \%)$ and only 31 $(18.1 \%)$ of them has normal BP while females were 152 (47.1\%) and 58 (38.2\%) has normal BP. Age for most of the respondents was less than 35 years 211 (65.3\%). Age between 36-45 years were 51 (15.8\%), almost half of them were pre-hypertensive 25 (49.0\%) (Table 1). Hypertension percentage was found to be increased with increasing in age, $3.3 \%$ of age group less than 35 years compared to $32.8 \%$ among age group 46 years and above. Also among those discovered to be hypertensive the percentage was $16.6 \%$ among younger age group compared to $24.6 \%$ among elderly groups. The intake of salt and sugar was also shown in Table 1.

Most of the respondents had higher education level in the study 229 (70.9\%), occupation and educational level have no association with risk of hypertension ( $\mathrm{P}$ value was 0.31 and 0.06 respectively). Furthermore, prehypertensive individuals represent 101 (44.1\%), while 259 $(80.2 \%)$ of the sample has physical activity of less than $150 \mathrm{~min} /$ week and pre-hypertension has highest percentages among both groups of physical exercise of more or less than $150 \mathrm{~min} /$ week (44\% and 48\%). Regarding obesity, nearly half of the respondents have BMI above normal 154 (47.7\%); hypertension was $3 \%$ among those having normal BMI, $12 \%$ among over weight group and $27 \%$ among obese group. Pre-hypertensive group had higher percentage of consumption of sugar [117 (48.5\%)] and salt [38 (49.4\%)]. Both sugar and salt intake had significant association with hypertension, the former has stronger association ( $\mathrm{P}$ value were 0.00 and 0.04 respectively).

The statistical associations between different variables showed that: $\mathrm{P}$ value was found highly significant, (equal or less than 0.05), among following variables: male sex, age, obesity (BMI); while the association was weak for physical activity $(\mathrm{P}=0.053)$.

\section{Logistic regression analysis}

Male sex has more than two times more chance to be hypertensive $\mathrm{P}=0.016$ (OR =2.096; 95\% CI, 1.150-3.821) when we used binary logistic regression to test statistical associations and risk factors for hypertension. High salt intake group has $30 \%$ higher probability to be hypertensive $(\mathrm{OR}=1.318)$, but this association was not statistically significant $(\mathrm{P}$ value $=0.388$ ). Male sex, elder age group of more than 45 years, obesity with BMI more than 30 , and high sugar consumption of more than $200 \mathrm{cal}$ were absolute 
risk factors for hypertension. Obesity $(\mathrm{OR}=3.8)$ had strong association with nearly four times risk compared to those having normal BMI (Table 2).

\section{Discussion}

The prevalence of hypertension in this study was estimated to be $27.6 \%$. This prevalence is comparable to other studies in Sudan. For instance, Bushara et al. showed that the prevalence of hypertension in urban area in north of Sudan was $35.7 \%$ and factors associated were increasing age, low educational level, diabetes mellitus, obesity, and central obesity (8). Bushara et al. showed that prevalence of hypertension in rural areas of north Sudan was 38.2\%, with a significant association with increasing age, obesity, illiteracy and diabetes mellitus (9). Hypertension in individuals with diabetes in Sudan was high around 44\%, while in Nuba tribe living in Sudan the prevalence of hypertension was estimated to be around 50\% $(12,17)$. The prevalence of hypertension in this study is also comparable to overall prevalence of hypertension in Sub-Saharan Africa (SSA), which was estimated to be $30 \%$, ranging from $16 \%$ at the age of 30 years to $44 \%$ at the age of 60 (18).

The increased prevalence of hypertension in this study might be attributed to obesity and rapid urbanization. Ahmed et al. have shown that the prevalence of obesity in Sudan was around $21 \%$ among 7,239 subjects. Their data showed that obesity was associated with hypertension (19). Importantly, obesity was one of the absolute risk factors for hypertension in this study. It worth mentioning, this study did not include pediatric population but obesity in Sudanese children was associated with hypertension. For instance, Salman et al. showed that the prevalence of obesity in Sudanese children was $10.5 \%$ and overweight was $14.8 \%$, both overweight and obesity were strongly associated with hypertension among primary schoolchildren in urban Sudan (20).

Due to high prevalence of hypertension in SSA, the World Health Organization (WHO) has supported interventions to decrease salt intake in SSA in order to decrease prevalence of hypertension in the region (15). In this study salt intake was significantly associated with hypertension, but was not an absolute risk factor in logistic regression analysis. However, high salt intake group has $30 \%$ higher probability to be hypertensive with an odd ratio of 1.3. Several studies have shown the link between salt intake and hypertension $(21,22)$. For example, in study of 102,216 adults from 18 countries and 5 continents, salt intake was associated with high BP (23).

The associated risk of sugar intake with hypertension was reported in several studies. Jayalath et al. showed in systemic review and meta-analysis of 6 large cohort studies (total population 240,508) among them 79,251 with hypertension, that sugar intake is associated with risk of hypertension (24). In meta-analysis of randomised controlled trials of 8 weeks or more, higher sugar intake was associated with significantly increases in systolic $(7.4 \mathrm{mmHg})$ and diastolic $(6.1 \mathrm{mmHg})$ BP (25). In systematic review of 12 studies that included 400,000 individuals, sugar intake was significantly associated with increased incidence of hypertension and increase in BP (26). The effect of sugar on BP is unfortunately dose dependent (24-26). Sugar intake is also associated with dyslipidaemia, type 2 diabetes and increase in risk of cardiovascular disease (27). In this study, sugar intake was one of absolute risk factors for hypertension in Sudanese individuals. This has an important public health impact in Sudan due to the fact that (I) Sudan is one of leading country in sugar production in the world (Kenana sugar factory is regarded as biggest integrated and diversified sugar complexes in the world); (II) the Food and Agriculture Organization of the UN (FAO) estimated in 2010 that sugar was the second source of dietary energy consumption in Sudan; (III) traditional Sudanese foods consumed on daily basis contain high amount of sugar $(28,29)$. Therefore, clinicians and health authorities in Sudan should encourage the public to decrease sugar and salt intake. Furthermore, this study endorsed the previous published observations that male sex and elder age group of more than 45 years are also risk factor for hypertension $(11,19)$.

This study is not without limitations. The cross sectional design may not allow for generalization of the results to the whole population. The role of genetic factors on high prevalence of hypertension and link with risk factors were not investigated. Despite the fact that $70.9 \%$ of the respondents had higher education level, occupation and educational level have no significant association with risk of hypertension. This may suggest the need to increase public awareness of the negative effect of sugar and salt on BP. Despite these limitations, this study is novel, important and pioneer in drawing attention of health professions and health policy makers to consider increasing awareness of the public to the association between high salt and sugar intake and hypertension.

\section{Conclusions}

The prevalence of hypertension is estimated to be $27.6 \%$. Hypertension in Sudanese individuals was associated with high sugar and salt intake, obesity and increase in age. 
Table 1 Characteristics of the respondents according to their hypertension status

\begin{tabular}{|c|c|c|c|c|c|c|}
\hline Variables & \multicolumn{4}{|c|}{ HTN status, n (\%) } & Total & $P$ value \\
\hline Sex & & & & & & $<0.01$ \\
\hline Male & $31(18.1)$ & $80(46.8)$ & $42(24.6)$ & $18(10.5)$ & 171 & \\
\hline Age group & & & & & & 0.00 \\
\hline 35 years or less & $68(32.2)$ & $101(47.9)$ & $35(16.6)$ & $7(3.3)$ & 211 & \\
\hline $36-45$ years & $14(27.5)$ & $25(49.0)$ & $10(19.6)$ & $2(3.9)$ & 51 & \\
\hline 46 years or more & 7 (11.5) & $19(31.1)$ & $15(24.6)$ & $20(32.8)$ & 61 & \\
\hline Technician & $14(33.3)$ & $15(35.7)$ & $10(23.8)$ & $3(7.1)$ & 42 & \\
\hline Staff member & $31(27.0)$ & $50(43.5)$ & $20(17.4)$ & $14(12.2)$ & 115 & \\
\hline Registrar & $9(45.0)$ & $10(50.0)$ & $1(5.0)$ & $0(0.0)$ & 20 & \\
\hline Employee & $16(27.1)$ & $29(49.2)$ & $12(20.3)$ & $2(3.4)$ & 59 & \\
\hline Education level & & & & & & 0.06 \\
\hline 2ndary level or less & $17(18.1)$ & $44(46.8)$ & $18(19.1)$ & $15(16.0)$ & 94 & \\
\hline Graduate or higher & $72(31.4)$ & $101(44.1)$ & $42(18.3)$ & $14(6.1)$ & 229 & \\
\hline Over weight & $20(17.1)$ & $53(45.3)$ & $30(25.6)$ & $14(12.0)$ & 117 & \\
\hline Obese or very obese & $4(10.8)$ & $13(35.1)$ & $10(27.0)$ & $10(27.0)$ & 37 & \\
\hline Sugar intake & & & & & & 0.00 \\
\hline$<200$ & $16(19.5)$ & $28(34.1)$ & $23(28.0)$ & $15(18.3)$ & 82 & \\
\hline$>200$ & $73(30.3)$ & $117(48.5)$ & $37(15.4)$ & $14(5.8)$ & 241 & \\
\hline Salt intake & & & & & & 0.04 \\
\hline Low to moderate consumption & $73(29.7)$ & $107(43.5)$ & $40(16.3)$ & $26(10.6)$ & 246 & \\
\hline High consumption & $16(20.8)$ & $38(49.4)$ & $20(26.0)$ & $3(3.9)$ & 77 & \\
\hline Total & $89(27.6)$ & $145(44.9)$ & $60(18.6)$ & $29(9.0)$ & 323 & \\
\hline
\end{tabular}

$P$ values $<0.05$ are considered significant; Pearson chi squared and $t$-test tests were used to check for significance between variables. HTN, hypertension; BP, blood pressure; BMI, body mass index. 
Table 2 Logistic regression analysis for risk factors of hypertension

\begin{tabular}{|c|c|c|c|c|}
\hline \multirow{2}{*}{ Variables } & \multirow{2}{*}{$P$ value } & \multirow{2}{*}{ OR } & \multicolumn{2}{|c|}{$95 \% \mathrm{Cl}$ for OR } \\
\hline & & & Lower & Upper \\
\hline Sex (male) & 0.016 & 2.096 & 1.150 & 3.821 \\
\hline Age group (elder group) & 0.000 & 1.822 & 1.307 & 2.540 \\
\hline $\begin{array}{l}\text { Physical activity less } \\
\text { than } 150 \mathrm{~min} / \text { week }\end{array}$ & 0.053 & 1.913 & 0.991 & 3.693 \\
\hline Obesity & 0.001 & 3.843 & 1.747 & 8.455 \\
\hline $\begin{array}{l}\text { Sugar intake (more than } \\
200 \text { Cal) }\end{array}$ & 0.001 & 0.355 & 0.196 & 0.644 \\
\hline High salt intake (high) & 0.388 & 1.318 & 0.704 & 2.466 \\
\hline
\end{tabular}

$P$ values $<0.05$ are considered significant. Age, obesity and high sugar intake are absolute risk factors for hypertension. OR, odds ratio.

Reduction of both sugar and salt intake is an important and cost-effective way for reducing hypertension and the risk of cardiovascular diseases (CVDs) and should be advocated by the health authorities and the public in Sudan.

\section{Acknowledgements}

Health Insurance Corporation, Khartoum State (HIKS), Sudan and Patients Helping Fund, Khartoum, Sudan.

\section{Footnote}

Conflicts of Interest: The authors have no conflicts of interest to declare.

Ethical Statement: An ethical clearance of the research was obtained from the Ethical Committee of the Faculty of Medicine-University of Medical Science and Technology, Khartoum, Sudan (IRB No. 00008867). Written informed consent was obtained from the patient for publication of this manuscript.

\section{References}

1. Dzudie A, Ojji D, Anisiuba BC, et al. Development of the roadmap and guidelines for the prevention and management of high blood pressure in Africa: Proceedings of the PASCAR Hypertension Task Force meeting: Nairobi, Kenya, 27 October 2014. Cardiovasc J Afr 2015;26:82-5.
2. Akinyemi RO, Izzeldin IM, Dotchin C, et al. Contribution of noncommunicable diseases to medical admissions of elderly adults in Africa: a prospective, cross-sectional study in Nigeria, Sudan, and Tanzania. J Am Geriatr Soc 2014;62:1460-6.

3. Nejjari C, Arharbi M, Chentir MT, et al. Epidemiological trial of hypertension in North Africa (ETHNA): An international multicentre study in Algeria, Morocco and Tunisia. J Hypertens 2013;31:49-62.

4. Ghannem H, Fredj AH. Epidemiology of hypertension and other cardiovascular disease risk factors in the urban population of Soussa, Tunisia. East Mediterr Health J 1997;3:472-9.

5. Goma FM, Nzala SH, Babaniyi O, et al. Prevalence of hypertension and its correlates in Lusaka urban district of Zambia: A population based survey. Int Arch Med 2011;4:34.

6. Tesfaye F, Byass P, Wall S. Population based prevalence of high blood pressure among adults in Addis Ababa: Uncovering a silent epidemic. BMC Cardiovasc Disord 2009;9:39.

7. Hendriks ME, Wit FW, Roos MT, et al. Hypertension in sub-Saharan Africa: Cross-sectional surveys in four rural and urban communities. PLoS One 2012;7:e32638.

8. Bushara SO, Noor SK, Ibraheem AA, et al. Prevalence of and risk factors for hypertension among urban communities of North Sudan: Detecting a silent killer. J Family Med Prim Care 2016;5:605-10.

9. Bushara SO, Noor SK, Elmadhoun WM, et al. Undiagnosed hypertension in a rural community in Sudan and association with some features of the metabolic syndrome: how serious is the situation? Ren Fail 2015;37:1022-6.

10. Balla SA, Abdalla AA, Elmukashfi TA, et al. Hypertension among rural population in four states: Sudan 2012. Glob J Health Sci 2014;6:206-12.

11. Noor SK, Elsugud NA, Bushara SO, et al. High prevalence of hypertension among an ethnic group in Sudan: implications for prevention. Ren Fail 2016;38:352-6.

12. Available online: http://www.who.int/ncds/surveillance/ steps/riskfactor/en/

13. The WHO STEPwise approach Surveillance of risk factors for non-communicable diseases 2011. WHO Press, Geneva.) National Heart, Lung, and Blood Institute. Clinical guidelines on the identification, evaluation, and treatment of overweight and obesity in adults: the evidence report. Obes Res 1998;6:51S-210S.

14. Guideline: Sugar intake for Adults and children, 
WHO, 2015.

15. Sookram C, Munodawafa D, Phori PM, et al. WHO's supported interventions on salt intake reduction in the sub-Saharan Africa region. Cardiovasc Diagn Ther 2015;5:186-90.

16. Chobanian AV, Bakris GL, Black HR, et al. Seventh report of the Joint National Committee on Prevention, Detection, Evaluation, and Treatment of High Blood Pressure. Hypertension 2003;42:1206-52.

17. Ahmed M el-B, Elmahadi EM. Pattern of blood pressure in African diabetics: report from Sudan. J Hum Hypertens 1995;9:899-901.

18. Ataklte F, Erqou S, Kaptoge S, et al. Burden of undiagnosed hypertension in sub-saharan Africa: a systematic review and meta-analysis. Hypertension 2015;65:291-8.

19. Ahmed MH, Ali YA, Awadalla H, et al. Prevalence and trends of obesity among adult Sudanese individuals: Population based study. Diabetes Metab Syndr 2017;11:S963-7.

20. Salman Z, Kirk GD, Deboer MD. High Rate of ObesityAssociated Hypertension among Primary Schoolchildren in Sudan. Int J Hypertens 2010;2011:629492.

21. He FJ, Li J, Macgregor GA. Effect of longer term modest salt reduction on blood pressure: Cochrane systematic review and meta-analysis of randomised trials. BMJ 2013;346:f1325.

22. Sacks FM, Svetkey LP, Vollmer WM, et al. Effects on

Cite this article as: Awadalla H, Elmak NE, El-Sayed EF, Almobarak AO, Elmadhoun WM, Osman M, Noor SK, Ahmed MH. Hypertension in Sudanese individuals and associated risk factors: the critical intersection between salt and sugar intake. Cardiovasc Diagn Ther 2018;8(4):432-438. doi: 10.21037/ cdt.2018.04.05 blood pressure of reduced dietary sodium and the Dietary Approaches to Stop Hypertension (DASH) diet. N Engl J Med 2001;344:3-10.

23. Mente A, O'Donnell MJ, Rangarajan S, et al. Association of urinary sodium and potassium excretion with blood pressure. N Engl J Med 2014;371:601-11.

24. Jayalath VH, de Souza RJ, Ha V, et al. Sugar-sweetened beverage consumption and incident hypertension: a systematic review and meta-analysis of prospective cohorts. Am J Clin Nutr 2015;102:914-21.

25. Te Morenga LA, Howatson AJ, Jones RM, et al. Dietary sugars and cardiometabolic risk: systematic review and meta-analyses of randomized controlled trials of the effects on blood pressure and lipids. Am J Clin Nutr 2014;100:65-79.

26. Malik AH, Akram Y, Shetty S, et al. Impact of sugarsweetened beverages on blood pressure. Am J Cardiol 2014;113:1574-80.

27. Basu S, Yoffe P, Hills N, et al. The relationship of sugar to population-level diabetes prevalence: an econometric analysis of repeated cross-sectional data. PLoS One 2013;8:e57873.

28. Institute of Developing Economic-Japan External Trade Orgnisation- Kenana Sugar Company (KSC) Available online: http://www.ide.go.jp/English/Data/Africa_file/ Company/sudan04.html

29. Available online: www.fao.org/fileadmin/user.../ SudanFoodInsecurityAssessment_NBHS_July10.pdf 